\section{Focusing Extension Resources to Diverse Clientele}

\author{
M.P. Garber ${ }^{1}$
}

Additional index words. nursery crops, market research, nursery operators, landscape architects, landscape contractors

Summary. Marketing techniques were valuable in the development of an extension and research support program for the diverse Georgia nursery industry. The support program was developed in three stages: 1) needs assessment and development of industry alliances, 2) initiation of a research program based on priority needs, and 3) technology transfer. The needs assessment was facilitated by the development of a distribution channel map for the Georgia landscape/nursery industry. The industry alliances developed early in the project facilitated conduct of the research program and technology transfer. The research component was identified from an informal needs assessment and qualitative information on industry relations inferred from the distribution channel map. The research results support the contention that landscape architects have a significant influence on demand for nursery crops and that nursery operators should treat this group as important customers. The focus for technology transfer is improved marketing procedures and more efficient working relationships between nursery operators and landscape architects. This includes development of new alliances at the industry/association level, improved marketing practices for nursery operators, and positioning extension publications to benefit multiple industry segments.

'Associate Professor

Department of Horticulture and Extension, Univ. of Georgia, P.O. Box 1209, Mon. GA 31793.
$\mathrm{D}$ ers and policy makers expect a higher return on their investment in university research and extension. This requires extension specialists to focus on the critical, high-return needs of clientele groups. Such an approach requires a greater investment of up-fronttime that will hopefully identify a single need that benefits multiple industry segments. This strategy could broaden the support base for extension specialists, focus limited resources to critical needs, and result in a higher return on the university investment

This paper summarizes how marketing techniques helped formulate and implement a support program for the Georgia landscape/nursery industry. The emphasis is on the extension activities of the program, specifically 1) assessment of industry relationships and needs, 2) development of industry alliances, and 3) transfer and implementation of research results.

The initial step in program development was to identify the various industry segments and their relationship to each other. An understanding of the relationship between industry segments proved valuable when selecting a single need that could benefit multiple industry segments. A marketing tool instrumental in this process is the distribution channel map. The channel map describes the movement of products through various manufacturing and marketing steps and is often displayed as a flow chart (Bingham and Raffield, 1990; Boone and Kurtz, 1986).

The distribution channel map for the Georgia landscape industry was developed similar to that segment of the industry is identified, in this case the grower or nursery operator, and then two questions are answered: 1) who is thecustomer of this segment and 2) who is the supplier(s) to this segment. The channel map for the Georgia industry is shown in Fig. 1. The distribution channel map can also be developed for a single product, such as field-grown trees, with greater detail (Garber, 1991a, 1991 b). Information espite static funding, industry leadof any unfamiliar industry or product. An initial

gathered at this stage may be primarily qualitative.

The channel map (Fig. 1) demonstrates that there are two channels of distribution for nursery crops: retail (garden centers and mass merchants) and landscape. Retail outlets and landscape contractors are the primary purchasers of plant material from nursery operators. These segments plus the nursery plant propagators receive considerable attention from extension programs. The landscape architects are not usually regarded as a part of the landscape/ nursery, since they do not grow or take possession of plants. They do, however, occupy a strategic position in the distribution channel (Garber, 1991c). They have a direct influence on demand for plant material in the landscape channel. In most cases, the decision on plant specification is delegated to landscape architects for large commercial, governmental, and resort complexes. Landscape architects also influence demand at garden centers by providing examples of appealing landscapes. This occurs when consumers observe plants in the landscapesdesigned by landscape architects and subsequently request the plants at garden centers.

The next step in program development was a survey of industry needs. The survey consisted of personal interviews with several propagators, growers, landscape contractors, and garden centers. Questions centered on the major areas of support needed by each segment, such as production, marketing, or regulatory issues.To match industry needs and current programs, a resource allocation chart was developed (Table 1). All segments of the industry were generally satisfied with the level and focus of production-related support programs (Table 1). An issue of increasing importance is that of regulatory requirements. This includes environmental, legal, and personnel items. Although opportunities exist for enhanced extension programs, some of the needs are being satisfied by extension and Dept. of Agriculture programs at the state level. Another need, and one not being addressed by any agency, is that of

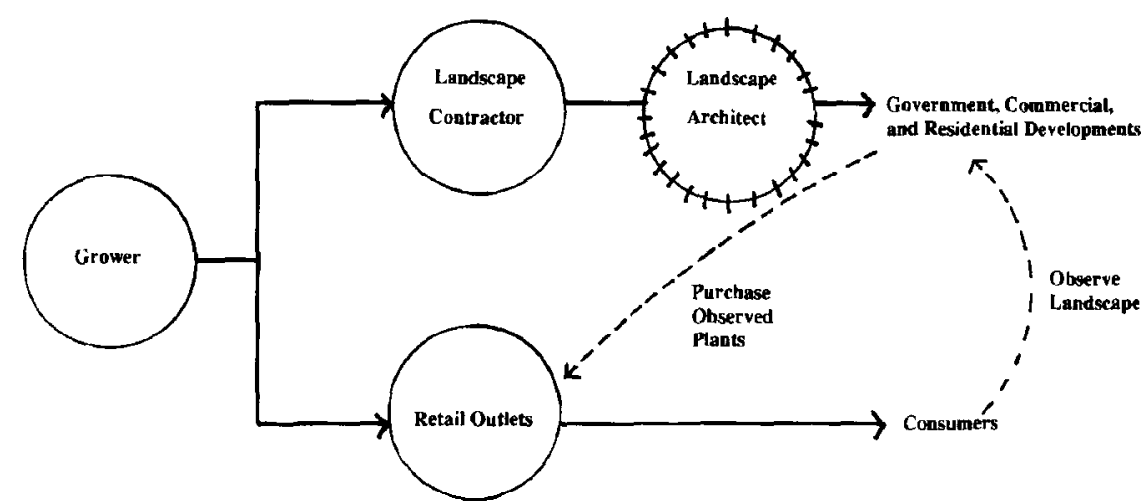

Fig. 1. Distribution channel map of the landscape/nursery industry highlighting the influence of landscape architects on the demand for plant material. Landscape architects influence consumer purchases at retail outlets through p/ant selection for commercial projects (dotted lines). 
Table 1. Resource allocation chart used to identity current program emphasis and needs for the nursery/landscape industry.

\begin{tabular}{lcccc}
\hline & & Support programs & Regulatory \\
\cline { 2 - 4 } Industry segment & Production & Marketing & + \\
\hline Propagation & $+^{I}$ & - & + \\
Container nursery & + & - & + \\
Field nursery & + & - & - \\
Garden center & + & - & + \\
Landscape contractor & + & - & + \\
\hline
\end{tabular}

Denotes that client groups are general/y satisfied with (+) or not satisfied (-) with current emphasis of support programs.

marketing assistance. All segments desire a better understanding of future plant material demand and how to market their goods and services. The grower segment is particularly interested in better marketing techniques because of the long lead time for plant production and ultimate supply.

A market research program directed toward landscape architects was developed to satisfy the need of nursery operators for improved marketing practices (Table 1) and to characterize the influence of landscape architects in the landscape industry (Fig. 1). Specifically, a survey of landscape architects in Georgia was conducted to determine their impact on the demand for plant material, plant material trends as viewed by landscape architects, the value of nursery operators marketing directly to landscape architects, and opportunities for growers and landscape contractors to help landscape architects achieve a high quality installed landscape.

Several programs, initiated before the survey, helped develop industry alliances and encourage participation by landscape architects. The Amer. Soc. of Landscape Architects (ASLA) agreed to cosponsor the survey with The Univ. of Georgia. The incentive for ASLA to participate is that the survey results could help forge a closer working relationship among growers, landscape contractors, and landscape architects (Benjamin, 1990; Garber, 1991c, 1991d). The groups affected by the survey results (growers, landscape contractors, and landscape architects) participated in the development of the survey instrument. The potential benefits for landscape architects was communicated through the Georgia ASLA Newsletter and personal presentations to Georgia ASLA section meetings.

The survey questions, methodology, and results have been reported previously (Garber and Bondari; 1992a, 1992b, 1992c). The results provide quantitative data that support the contention that landscapearchitects influence the demand for a significant portion of nursery crops and should be treated as important customers by nursery operators. For instance, landscape architects in Georgia specify about $\$ 85$ million of plant material (Garber and Bondari, 1992a) which compares to an estimated value of $\$ 200$ million for nursery crops produced in Georgia (Brooker and Turner, 1989). About $61 \%$ of all landscape architectural firms either determine or recommend the production nursery where the landscape contractor ob-

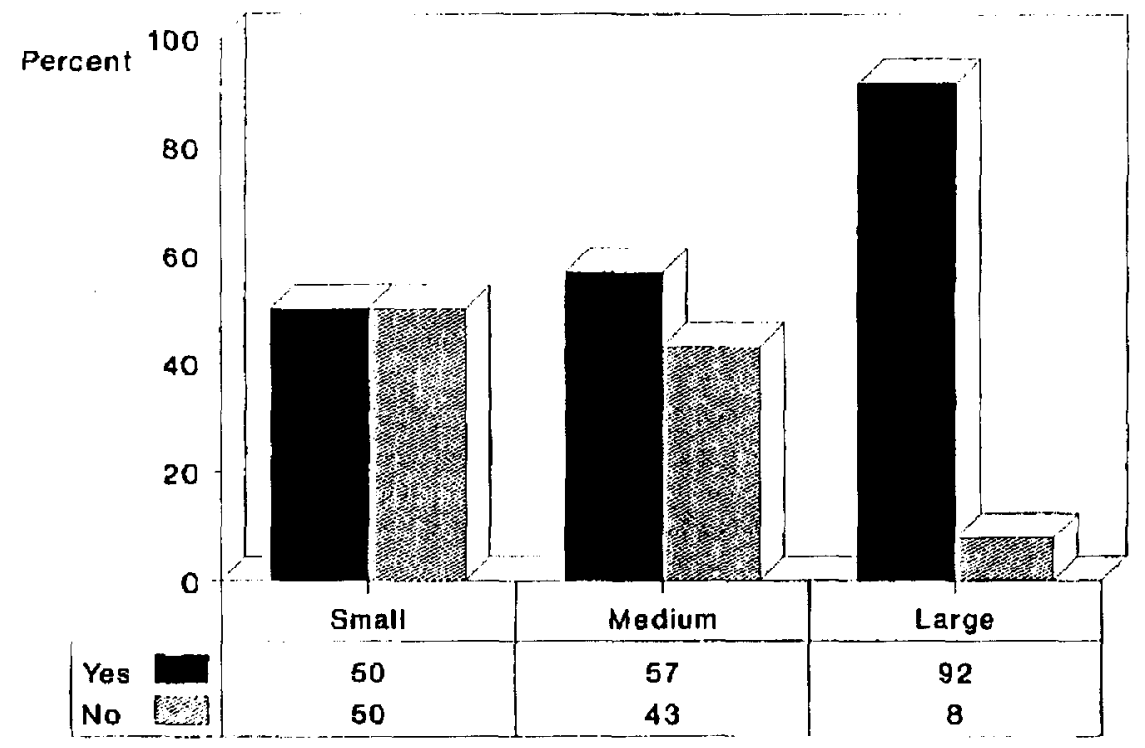

Fig. 2. Response of landscape architects to the question, "Do you determine/recommend the production nursery where your landscape contractor obtains plants?" The results are for all size firms. tains plants (Fig. 2). More importantly, $92 \%$ of the large firms, which account for $67 \%$ of the value of plants specified, are involved in selection of the production nursery (Fig. 3). The results demonstrate that producers could enhance the effectiveness of their marketing program by direct communications with landscape architects. The results also provide useful information for extension specialists to target educational programs to landscape architects and thereby assist nursery operators.

Technology transfer activities focused on the individual nursery operators and on the industry/association level. The first step was a review of findings with several landscapearchitectural firms and the Atlantasection of ASLA. The survey results indicated that $66 \%$ of landscape architects were located in the metro Atlanta area. This exchange provided greater insight into the results and allowed for gathering of additional information. Proposed recommendations for nursery operators were also presented for feedback by landscape architects. After reviewing the results with the customer group, landscape architects, the results and recommendationswere reviewed with nursery operators. Several recommendations have been accepted by the landscape industry. For instance, the survey indicated that botanical and public gardens are the most widely used source of information used by landscape architects to make decisions on which plants to specify (Garber and Bondari, 1992c). The Atlanta Botanical Garden plans to host the various industry segments (growers, landscape contractors, and landscape architects) and discuss which plants perform well in the Atlanta landscape. At the association level, the Georgia Green Industry Assn., which consists of growers, garden centers, and landscape contractors, now provides free admission to their annual trade show for all members of the Georgia ASLA. Trade shows were identified by the landscape architects as a valuable source of information on potential plants to specify (Garber and Bondari, 1992c).

The landscape architects expressed a need for more information on cultural requirements of plantsand recommendations on specific plants for specific sites, e.g., more technical information organized from the user perspective. Nursery operators are now encouraged to group plant availability listings by landscape use. This includes grouping by location, e.g., wet areas, dry areas, and full sun; or mature size, e.g., tall trees and short trees. A recent extension service publication that meets these needs is the Compilation of Low-maintenance Plants for Georgia Landscapes (Corley et al., 1991). Georgia landscape architects plan to identify additional information needs for future extension publications. This allows extension personnel to play an important role in the proper use of plants in the landscape. These publications should be of value to multiple industry segments. If extension service 


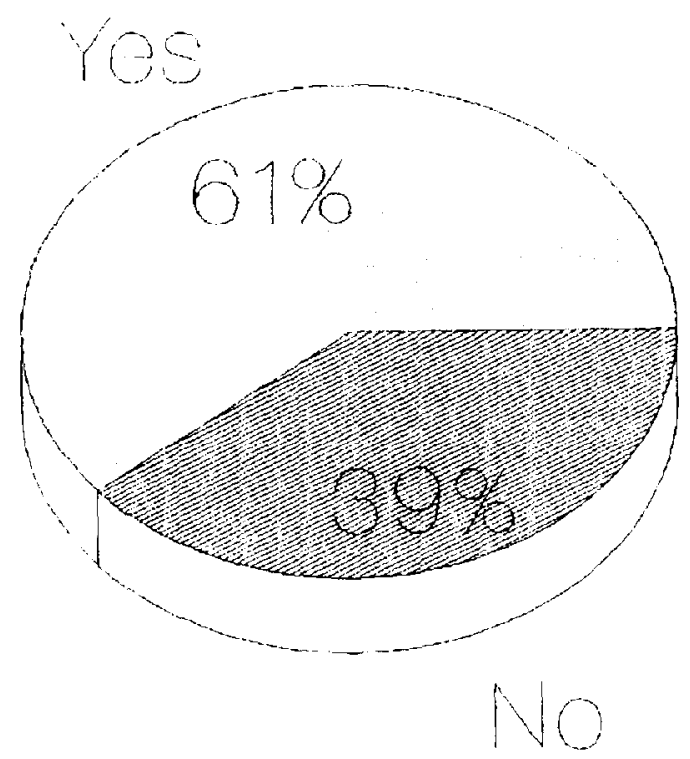

Fig. 3. The response of small, medium, and large landscape architectural firms to the question, "Do you determine/ recommend the production nursery where your landscape contractor obtains plants?" Firm size is based on 1990 wholesale value of plant material specified: small (less than $\$ 200,000)$, medium $(\$ 200,000$ to $\$ 999,000)$, and large ( $\$ 1$ million or more).

publications, such as the one mentioned above, are communicated to user (landscape architects) and producer (nursery operators) groups, extension personnel could also contribute to the alignment of supply and demand.

This project provides examples of how extension personnel might position their programs to assist producers of various commodities with their marketing programs. Key steps include identification of the industry segments that influence marketing of the horticultural product, identification of customer needs relative to use of the product, and collection and dissemination of information that meets these needs. This approach also raises the question of whether extension specialists should align their programs strictly by commodity (nursery, floriculture, or fruit crops) or perhaps by discipline such as marketing or environmental regulations. Development of programs around disciplines might facilitate working with multiple commodities or multiple industry segments within a commodity. In this case, the emphasis on marketing allows one specialist to assist several groups including nursery operators, landscape contractors, landscape architects, and the botanical gardens. The economic return on the university investment should be higher and the industry support base broader. In this role, extension specialists assist multiple industry segments and function as the glue that pulls the industry segments together.

In summary, the support program developed for the Georgia landscape/nursery industry should enhance the marketing programs of nursery operators and provide a basis for greater interaction among landscape architects, landscape contractors, and growers. The results also demonstrate that marketing techniques such as the distribution channel map (Fig. 1) and customer/client needs assessment (Table 1) can be used to focus limited extension resources to a high priority industry segment (landscape architects) with a single program (marketing assistance) that benefits multiple segments of the landscape/nursery industry.

\section{Literature Cited}

Benjamin, P.C. 1990. ASLA and industry leaders hammer out "New Alliance." Nursery News 5(12)11.

Bingham, F.G. and B.T. Raffield. 1990. Business to business marketing management. Irwin Press, Boston.

Boone, L.E. and D.L. Kurtz. 1986. Contemporary marketing. Dryden, Chicago.

Brooker, J.R. and S.C Turner. 1989. Trade flows and marketing practices. Coop. Ser. Bul. 358. Univ. of Tennessee Agr. Expt. Sta.

Corley, W.L., J.T. Midcap, and G.L. Wade. 1991. Compilation of low-maintenance plants for Georgia landscapes. Univ. of Georgia Tech. Bul. H-91-009.

Garber, M.P. 1991a. In-ground ornamental tree production. Univ. of Georgia Tech. Bul. H-91-003.

Garber, M.P. 1991 b. Market opportunities for in-ground trees. Univ. of Georgia Tech. Bul. H-91-006.

Garber, M.P. 1991c. Have you hugged your landscape architect today? Georgia Green Ind. Nwsl. 2(1):13-18.

Garber, M.P. 1991d. "New Alliance" to survey needs of landscape architects Nursery News 6(4):20

Garber, M.P. and K. Bondari. 1992a. Landscape architects as related to the landscape/nursery industry: I. Impact on demand for plant material. J. Environ. Hort. (In press).

Garber, M.P. and K. Bondari. 1992b. Landscape architects as related to the landscape/nursery industry: Il. Selection of the production nursery and plant availability. J. Environ. Hort. (In press).

Garber, M.P. and K. Bondari. 1992c. Landscape architects as related to the landscape/nursery industry: Ill. Sourcesof plant material information J. Environ. Hort. (In press). 